\title{
Disfunção miccional - doença funcional e social
}

\section{Miccional dysfunction - functional and social disease}

\author{
LISIEUX EYER DE JESUS, TCBC RJ \\ T-CIPE. Cirurgião e Urologista Pediátrico Hospital Universitário Antônio Pedro, UFF e Hospital Federal dos Servidores do Estado.
}

A incidência de disfunção miccional, incluindo adultos e crianças, é assustadoramente alta e parece estar em ascensão. Autores norteamericanos sugerem que até $1 / 5$ da população pediátrica é afetada. As cifras são ainda maiores para as mulheres após a menopausa e homens, em processo de envelhecimento, acima dos 65 anos.

Alguns dados evidenciam que uma história de disfunção miccional na infância está relacionada a uma maior incidência de queixas de incontinência urinária entre mulheres adultas que consultam ginecologistas, ainda que os sintomas da infância tenham sido controlados anteriormente. Tudo sugere que as mudanças hormonais determinadas pela puberdade e menopausa possam ser determinantes para a expressão clínica dos distúrbios miccionais em pacientes do sexo feminino. Nos homens, as doenças prostáticas confluem com as doenças funcionais para causar uma prevalência alta de distúrbios de função miccional.

Além das consequências nosológicas imediatas, principalmente as decorrentes das infecções urinárias de repetição e do refluxo vesicoureteral sintomático, sobretudo em crianças, é importantíssimo reconhecer as implicações sociais da doença. Entre as crianças acometidas pela incontinência, urge-incontinência e micção de alta frequência erguem-se barreiras sociais na escola e dificuldades no convívio familiar e extrafamiliar. As longas viagens de carro são impraticáveis, estadas na casa de outras crianças, assustadoras. A intimidação e o estigma podem ser suficientes para dar margem a distúrbios de comportamento, auto-exclusão social e problemas escolares.

Para tornar as coisas ainda piores, a crença popular afirma que as disfunções miccionais da criança são secundárias à problemas comportamentais ou educacionais, e, frequentemente, dá margem aos tratamentos psicológicos insuficientes sem um tratamento urológico simultâneo (porque estamos diante de um distúrbio funcional neuro-fisiológico) ou punições "educativas". Os problemas comportamentais nessas crianças, realmente comuns, estão frequentemente ligados a distúrbios neuropsiquiátricos de base, em especial a Desordem por Déficit de Atenção com Hiperatividade (DDAH), ou são secundários aos problemas sociais determinados pela doença neuro-urológica. Eles vêm depois ou associados ao problema urológico, não como causa da disfunção.

Na população idosa um corolário raramente reconhecido das síndromes de disfunção miccional, representadas, em sua maioria, por bexiga hiperativa e síndromes de urgência e urge-incontinência é um aumento de frequência de fraturas por quedas acidentais causadas pela extrema pressa do paciente em encontrar um banheiro próximo. Dados de literatura internacional relacionam diretamente síndromes disfuncionais com a incidência de fraturas na população idosa.

O tratamento das disfunções miccionais pode ser bastante difícil. Os anticolinérgicos, linha mestra do tratamento, têm resposta insatisfatória em cerca de 30\% da população tratada e um índice alto de efeitos colaterais. A necessidade de uso crônico de medicação e a alta incidência de paraefeitos extremamente desconfortáveis para o paciente induzem a uma frequência desproporcional de abandono terapêutico. Os custos da medicação são significativos, em especial com relação aos derivados anticolinérgicos mais novos no mercado, associados a uma menor incidência de efeitos colaterais e de abandono terapêutico. Os métodos não farmacológicos ainda têm uso restrito, seja por uma popularidade ainda limitada no Brasil (caso das técnicas de eletroestimulação) ou pelas dificuldades técnicas e logísticas envolvidas (por exemplo, com as técnicas fisioterapêuticas de biofeedback).

Temos feito progressos, há grupos brasileiros de pesquisadores responsáveis por inovações importantes nesse campo, seja para estudo da epidemiologia do problema no Brasil, seja para o diagnóstico, por exemplo a descrição pioneira das técnicas de ultrasonografia dinâmica pelo grupo da Universidade Federal de Minas Gerais ${ }^{1}$ e seja para a terapêutica, por exemplo as colaborações dos grupos do Rio de Janeiro, São Paulo e Bahia a respeito de técnicas de eletroestimulação terapêutica em crianças, publicadas pela primeira vez no Brasil nesta revista ${ }^{2}$.

A disfunção miccional é uma das doenças do século e precisa ser desmistificada. Na criança, precisa perder o rótulo de doença comportamental, psicológica ou autolimitada. No adulto precisa ser reconhecida como um fator de alta morbidade e gerador de altos custos, na forma de fraturas e dispositivos de controle de incontinência. E esta é uma tarefa para todos os médicos, enquanto educadores em saúde da população.

\section{REFERENNCIAS}

1. Filgueiras MF, Lima EM, Sanchez TM, Goulart EM, Menezes AC, Pires CR. Bladder dysfunction: diagnosis with dynamic US. Radiology. 2003;227(2):340-4.

2. Jesus LE, Nery K. O uso da neuromodulação no tratamento das disfunções de eliminações. Rev Col Bras Cir. 2007;34(6):392-7. 